\title{
Aspects that Pose Challenges in the Teaching of Mathematics at Grade 3 Level
}

\author{
1Maphetla M Machaba \\ 2Moipone E Lenyai \\ 1Department of Early Childhood development, machabmm@unisa.ac.za \\ 2Department of Early Childhood development, lenyaem@unisa.ac.za \\ University of South Africa (UNISA), PO Box 392 Pretoria 0003
}

\section{Doi:10.5901/mjss.2014.v5n2p535}

\begin{abstract}
The mathematical problems encountered by Grade 3 children are a burning issue to many countries. Given some factors contributing to poor performance, attention will be focused on those aspects of mathematics that pose challenges to Grade 3 children and their teachers. The outcome of the research will provide Grade 3 teachers with guidelines on teaching children who experience mathematical difficulties. Studies have been conducted on mathematical issues in other countries, but only a few have been conducted in disadvantaged Foundation Phase schools in South Africa. The problem of poor mathematical performance is not experienced in South Africa only, it is a universal problem
\end{abstract}

Keywords: mathematics, mathematical difficulties, Foundation Phase, Mathematical knowledge

\section{Introduction}

All children encounter some difficulties throughout their school careers - language, attitude, and mathematical difficulties (Van Kraayenoord, 1998: 370-371\& Elkins; Brown; Askew; Baker; Denvir \& Millet,). The aim of this study is to investigate aspects that pose challenges in the teaching of mathematics at Grade 3 level. The emphasis will, therefore, be on mathematical difficulties. The aim is, to identify and help those children who experience mathematical difficulties in the beginning of their school careers. If these mathematical difficulties are not identified and remedied soon enough, the children may become mathematically incompetent for the rest of their lives. Mathematics plays a vital role in the lives of all people and every individual has to possess some form of numerical competence in order to go through life successfully. For example, you need some basic level of mathematical competency to count how many cattle you have, how many would remain if a certain number is sold and so forth. It is, therefore, a necessary competence we all have to possess to some degree. Thus, it is very essential that educators identify mathematical difficulties and intervene in the beginning of a child's school career for the latter to have a sound foundation to build on. It is also government policy that all children should be taught mathematics, because it provides very important and necessary life skills that cannot be done without.

Although this study concentrates on mathematical difficulties it does not mean that other difficulties such as language and attitude are irrelevant or inferior. Scholastic difficulties are closely intertwined and cannot be isolated from one another. Numeracy barriers can be identified. There are also other extrinsic barriers originating from the learner's environment at school or at home, for example language; socio-economic; inflexible curriculum; language and communication; attitudes; lack of access to basic services; poverty and underdevelopment. Among the factors which place children at risk of failure are inappropriate and inadequate provision of support services; lack of enabling and protective legislation and policy; lack of parental recognition and involvement; disability and lack of resource development strategies. There are intrinsic barriers like deficiencies in themselves that contribute to children having special needs. A learner often fails to benefit from school because of a combination of these factors. (Department of Education, 1997:82)

(Mastropier \& Scruggs 2004:410; Mednick, 2007:174) assert that children who experience barriers to learning will also need to gain proficiency in mathematics to fully participate in society. For this to occur, teachers must be competent in a variety of teaching techniques that will allow children who experience learning barriers -as well as children with other diverse, learning needs-to reach their full potential in mathematics. Mednick, (2007:174) claims that all students, regardless of their barriers, backgrounds, personal characteristics physical challenges, must have opportunities to learn mathematics. Mastropier \& Scruggs (2004:410) points out that often children who experience numeracy barriers, 
however not much is said about why this may be so.

Furthermore, Groark, Mehaffie and Greenberg, (2007:3) and Joiner (1978:4) have clearly documented that the early identification of learner's who experience learning barriers is of vital importance not only to help them make better progress, but also to become participating members of society. On the one hand, it is important to identify children who experience learning barriers as early as possible so that services can minimise or eliminate learning barriers, but on the other hand, it is also important to avoid placing harmful labels on young children that lead to lower expectations for achievement. If learner's who experience barriers to learning can be identified at an early stage of development, they will stand a better chance to be successful since the problem will be activated.

\section{Literature Review}

The research aims to establish the approaches teachers use, other difficulties teachers experience and which aspect of mathematics is most problematic when teaching mathematics computations. It also aims to establish how teachers resolve the problem with the aim of developing a support programme for foundation phase teachers.

\subsection{Teachers' mathematical knowledge}

Teachers must know the subject matter in order to teach it effectively. Therefore, it is important that they possess mathematical knowledge. Cooney (1999:163) asserts that formerly, our conceptions of teacher knowledge consisted primarily of understanding what teachers knew about mathematics. Mathematical knowledge alone does not translate into better teaching. Cooney (1999:253) asserts that teachers need at least three kinds of knowledge to be effective in choosing worthwhile tasks, orchestrating discourse, creating an environment for learning and analysing their teaching and children's learning: knowledge of mathematics, knowledge of children and knowledge of the pedagogy of mathematics.

The teacher should know how to use language effectively in order to transfer knowledge. Failure to do so only exacerbates the children's mathematical problems. Margolinas, Coulange and Bessot (2005:206) argue that a teacher's knowledge is a very significant topic for mathematics education.

Shulman (1986) concurs and identifies content knowledge, pedagogical knowledge and pedagogical content knowledge as components of the professional knowledge of teachers. This implies that the teacher should not only possess academic knowledge, but should also be able to impart it in an understandable manner. It is vital that the vehicle of the teacher's thoughts and knowledge should be clear and vivid to the child. Steinbring (1998:159), therefore, asserts that, "a new kind of professional knowledge for mathematics teachers is needed, a kind of a mixture between mathematics content knowledge and pedagogical knowledge".

Askew and others (1997:21) assume that practicing lessons in the classroom is the major factor influencing learning outcomes. They also allege that teachers' beliefs and knowledge and practices in the classroom like lesson planning will inform and influence the lessons. A teacher might believe that children learn best through direct instruction. But if the teacher's knowledge of the subject is incorrect or limited, what the children are going to learn will be affected by the teacher's lack of knowledge (Askew et al, 1997:23). This is why it is important that the teachers have a good knowledge of what they are going to teach.

The teacher should also have a good knowledge of the child's prior knowledge in order not to teach children what they already know or something that is too difficult for them to grasp (Askew et al., 1997:23). Finally, the teacher has to use suitable teaching methods in order to render his or her knowledge of mathematics accessible to children (Askew et al, 1997:23). The teacher might be a mathematics genius, but if he or she does not have sound teaching methods, he or she will not be able to reach the children; and effective learning would not take place.

Even and Tirosh (1995:164) also argues that a, "teacher who pays attention to where the children are conceptually, can challenge and extend children's thinking and modify or develop appropriate activities for children". If the teacher and her children understand concepts he or she will have better control and direction of classroom activities.

Appropriate mathematical activities can be developed to the level of understanding the children. It is essential to understand the children and their feedback not only the content, as content can only be understood meaningfully if it is well presented.

Kaufmann, Handl, and Thony (2003:565) and Kennedy (2000:95) argue that faulty conceptual knowledge might hamper the successful acquisition of calculation skills. Therefore, for the children to understand mathematics with fewer chances of developing difficulties, they should possess a clear understanding of the concepts. Without conceptual 
knowledge, the child might lack further understanding of underlying mathematical problems. Resnick (1989:162) says that knowledge is necessary to allow the flexible and adaptive application of numerical and arithmetical knowledge; and like all knowledge it is not directly absorbed, but is constructed by each individual. As such, children should be active participants in the learning process.

Baroody (2003:6) asserts that the transfer of learning might not take place until numerical and arithmetical knowledge (counting, factual and procedural) becomes meaningful. According to Perry (2000:182), the higher mathematical achievement levels of Asian children, in relation to their American peers is partly derived from the fact that Asian mathematics lessons incorporate more explicit teaching of conceptual knowledge than those of the Americans. Perry (2000:182) points out that meaningful explanation promotes problem-solving competence; in other words, good instruction should make a difference in children developing an understanding of mathematical concepts This then, makes it imperative for the mathematics teacher not only to know the concepts, but also how to impart them to the children in a language they can understand.

Copley and Nunes (1999) found that the informal handling of mathematical procedures and concepts yields better learning effects than formal school mathematics, because informal learning is meaningful (as it is linked to everyday activities), whereas formal learning is rather abstract (as it occurs from any context) and sometimes even requires the children to suppress their informal numerical knowledge. It is, thus, important that children are encouraged to work together and find solutions to problems while discussing such problems informally. Learning becomes fun and children are encouraged to participate.

Poulson (2001:41) argues that in an effort to enhance primary teachers' knowledge of the subject matter, and their professional expertise, subject-specific pedagogy is the assumption that teachers who know more teach better. The more knowledge a teacher possesses the better his or her teaching becomes. Thus Shulman (1986), according to Poulson, alleges that research about teaching, studies on teachers' knowledge and thinking are regarded as important aspects of educational research.

Poulson (2001:42) termed this type of study "pedagogical content knowledge" and claimed that it is a distinctive part of the teacher's knowledge base. Indeed, subject-specific pedagogy could be very effective in teaching a subject like mathematics. This type of teacher training would result in the production of better subject-specific teachers which, in turn, would improve the children's understanding of the specific subject. This is what South Africa should look at in an effort to reduce the number of children experiencing difficulties in mathematics.

\subsection{A child's conceptual knowledge}

According to Donlan (1998:77), conceptual knowledge is the understanding of the principles governing the domain and the interrelation between pieces of knowledge in a domain (understanding or principled knowledge) although this knowledge does not need to be explicit. Donlan (1998:77) defines procedural knowledge as action sequences for solving problems. It is important that the children are taught these principles in such a way that they understand them, rather than by rote.

Donlan (1998:75) says that conceptual knowledge and procedural knowledge are much of what children learn in the course of their development and they develop in tandem rather than independently, without question. In contrast, school-age children are described as having impoverished conceptual understanding that leads to their generating flawed and illogical procedures for solving multidigit subtraction problems, decimal fractions and other mathematical tasks. Thus, it is important for children to be taught concepts so that they understand mathematics more easily.

Piaget essentially sees the child as actively adapting to his or her environment, "from the inside out", and Vygotsky sees the child as active but essentially mediated, "from outside in" (Donald et al., 2002:84). This implies that conceptual knowledge should be taught from the known to the unknown. For example, the teacher should begin with what the children know and proceed to what they do not know.

\subsection{Language issues in teaching mathematics}

According to Naude, Pretorius and Vandeyar (2002:293-294), many Grade 1 children enter South African schools having various academic and learning difficulties that might occur as a result of limited language proficiency. A child with limited language proficiency may continue to learn and understand at a slower rate. This explains why Grade 3 children who receive tuition through a language other than their own find it difficult to understand numerical concepts as they also struggle to master the medium of instruction itself, because language and thought are interwoven. Limited language 
proficiency leads to learning difficulties. A child has to be competent in expressive and receptive languages in order to understand and carry out academic tasks including mathematics (Naude et al, 2002:294). Children should also be able to commit what they learn to memory and be able to reproduce it when needed. It goes without saying that lack of language proficiency would be an impediment for children at Foundation Phase. Thus, teachers need to be patient in teaching concepts such as minus, divide and so forth. Mercer (2006:508) argues that the tendency of mathematics educators and policy makers to emphasise the distinction between the subject language of mathematics and more informal talk can hinder the process of inducting children into mathematics practices.

(Mercer, 2006:507) argues that group activities offer valuable opportunities for children to construct solutions for themselves through talking which would not be found in whole-class teaching. This method encourages children to participate actively in finding solutions to problems while, at the same time, using language to communicate. In so doing, children are able to understand better and view mathematical exercises as everyday problems rather than something only related to the school environment and a special language - mathematical jargon. Vygotsky (1978) stresses the significance of language as a psychological and cultural tool (Mercer, 2006:508). He further argues that the social involvement in problem-solving activities constitutes an important factor for individual development (Mercer, 2006:508). He charges that intermental (social) activity, mediated through language, can promote intramental (individual), intellectual development. The utilisation of language and examples the child can associate with; and those that stem from his immediate environment, will engender better understanding and enable the child to relate the process in his own words. The children' capacity will also be stimulated.

There are two ways of interaction through which the spoken language can be related to the learning of mathematics in schools. The first is teacher-led interaction with children -the teacher guides the children in their development and understanding which can be important in the children's induction to discourses, associated with the particular knowledge domains. This is the concept of dialogue teaching propounded by Alexander (2000). "It concerns more subtle aspects of interaction such as the extent to which teachers elicit children's own ideas about the work they are engaged in, make clear to them to discuss errors and misunderstandings and engage them in extended sequences of dialogue about such matters" (Mercer, 2006:509). "Dialogic" strategies, according to Mercer (2006:510), achieved better learning outcomes.

Alexander (2004:32) suggests that dialogic teaching is a method that employs the power of talk to encourage and expand the children's thoughts and advance their learning and understanding. It involves both the teacher and the children and relates to teaching across the curriculum. It is an approach that is grounded in the principles of collectively, reciprocity, cognition and observation. Dialogical teaching, therefore, requires children to be actively engaged in doing as well as discussing what the lesson is about. This approach as such, is good in the teaching of mathematics whereby children have to handle concrete objects and explain what they see and, in tandem, also learn the concepts. Dialogic teaching is characterised by certain features of classroom interaction, such as:

- questions that are structured to provoke thoughtful answers.

- answers that provoke further questions and are seen as the building blocks of dialogue rather than its terminal point.

- individual teacher-child and child-child exchanges that are chained into coherent lines of enquiry rather than left stranded and disconnected. In this manner, the children experience the learning process as cooperative activity.

The second context of interaction in which spoken language can be related to the learning of mathematics in schools is that of peer group interaction. By working in pairs or groups, children become involved in interactions that are more "symmetrical" than those of teacher-pupil discourse and have different kinds of opportunities for developing reasoned arguments and describing events (Mercer, 2006:510). The child does not only learn mathematics, but also social interaction. Teachers can help children to gain relevant knowledge of numerical procedures, terms, concepts and operations. They can also help children to learn how to use language in order to work effectively and to jointly enquire, reason, consider information, share and negotiate ideas; and make joint decisions. This kind of guidance is not usually offered (Mercer, 2006:510).

According to Vaidya (2008:717), some children suffer from dyscalculia which is characterised by a poor understanding of the number concept and the number system characteristic of their age group. Such children experience difficulties with counting; learning abstract concepts of time; direction learning; and recalling facts, sequence of past and future events; and giving and receiving change. They also fail to use rules and procedures to build on known facts. For instance, they may know that $3+5=8$, but would fail to deduce that $5+3=8$. Such children are generally said to have difficulties in learning Mathematics. Without identification and remediation, these children would not be able to be 
numerically functional.

Mathematics is a "second language" and should be taught as such. It constitutes formal learning of concepts that have hitherto not been frequently used and known to many of the children. Thus, they would also seem to be learning a different language to the one they use at home. The conceptual aspects of mathematics learning are connected to the language. It is exclusively bound to the symbolic representation of ideas. Most of the difficulties in mathematics result from underdevelopment of the language of mathematics (Sharma, 1989).

Teaching the linguistic elements of mathematics language is sorely neglected. The syntax, terminology, and the translation from English to mathematical language, and from mathematical language to English must be taught directly and deliberately. Consequently, mathematics language can pose challenges for children. For a teacher to reach her children, she should have an understanding of the "mathematics language". An added problem is that certain mathematics terms such as "hypotenuse" are not found in everyday conversations

\section{Research Methodology}

The qualitative approach was used in this study to explore the views of grade three teachers regarding the approaches they use in teaching and learning of mathematics computation. We opted for this approach as it allows researchers to gain insight into the inner experience of participants, to determine how meanings are formed through culture, and to discover rather than test variables (White, 2005:81; Corbin \& Strauss, 2008:12). To collect data we used semi- structured interview as it helped to explain in detail what approaches teachers use when they teach computations in mathematics. For the purpose of this paper, we interviewed and observed five teachers from five different schools. The interviews were held during school time and lasted approximately 1-1/2/2 minutes. We conducted individual face-to-face interviews and did the observations with all the five teachers.

\section{Conclusion}

The data analysis indicated that the aspects that were most problematic vary from one school to the other and from one person to the other. Now with the situation here in SA, we are in an under developed environment, we have children from different backgrounds and there is a problem of language. In terms of the concept and content, the problem is mathematical terminology, for example the term "tessellation" must be translated into different languages.

\section{References}

Alexander, P. (2004). Towards dialogic teaching. Rethinking classroom tasks. Worcester, Massachusetts: Davis.

Alexander, R.J. (2000) Policy and Practice in Primary Education: local initiative, national agenda, London: Routledge.

Askew, M., Brown, M., Baker, D., Denvir, B., \& Millett, A. (1998). Is the National Numeracy Strategy research-based? British Journal of Educational Studies, 46(4), 362-385.

Baroody, A \& Dowker, A. (2003). The development of arithmetic concepts and skills: constructing adaptive expertise. USA: Library of Congress Cataloguing- in- Publication Data.

Cooney, T.C. (1999). Conceptualizing teachers' way of knowing. Educational Studies in Mathematics, 38:163-187.

Copley, J. (Editor). (1999). Mathematics in early years. Reston, VA: National Council of Teachers of Mathematics.

Corbin, J. and Strauss, A. (2008). Basics to qualitative research 3rd (Ed) USA: Library of Congress Cataloguing- in- Publication Data.

Croark, C.J, Mehaffie, K.E, McCall, R.B and Greenberg, M.T. (2007). Evidence-based Practices and Programs for early childhood. United Kingdom: Sage.

Department of Education. (1997). Quality education for all overcoming barriers to learning and development.28 November 1997. Report of the National Commission on Special Needs in Education and Training (NCSNET). National committee on Education Support Services (NCESS). Pretoria: Department of Education.

Donald, D., Lazarus, S. \& Lolwana, P. 2002. Educational psychology in context.(2nd Ed). Cape Town: Oxford.

Donlan, C. (1998). The development of mathematical skills. (Ed) UK: Library of Congress Cataloguing in Publication Data.

Elkins, J. (2007). Learning disabilities: Bringing fields and nations together. Journal of Learning Disabilities, Vol. 40, $392-399$.

Even, R., \& Tirosh, D., (1995). Subject - matter knowledge and knowledge about students as sources of teacher presentations of the subject matter, Educational Studies in Mathematics, 29, 1 - 20.

Hierbert, R., Martland, J. \& Stafford, A. (2000). Early numeracy: Assessment for teaching and intervention. London: Chapman.

Joiner, L.M. (1978). Identifying child's with special needs: A practical guide to developmental screening. Florida: Learning Publications, Inc.

Kaufmann, L., Handl, P., \& Thony, B. (2003). Evaluation of a numeracy intervention program focusing on basic numerical knowledge and conceptual knowledge. 36 (6), 564-573. 
Kennedy, L.M., and Tipps, L. (2000). Guiding children's learning of mathematics, 9th Ed. United Kingdom: Library of Congress Cataloguing- in- Publication Data.

Margolinas, C., Coulange, L., \& Bessot, A. (2005). What can the teacher learn in the classroom? Educational Studies in Mathematics 59, 205-234.

Mastropier, M. A., \& Scruggs, T.E. (2004). The inclusive classroom strategies for effective instruction. (2nd Ed.). United States: Library of Congress Cataloguing- in Publication Data.

Mednick, M. (2007). Supporting children with multiple disabilities. (2nd Ed). England: Continuum International Publishing group.

Mercer, N. (2006). Teaching children how to use language to solve maths problems. 20(6).Author please give the name of the Journal in which the article appears: DM $<$

Naude, H., Pretorius, E. \& Vandeyar, S. Teacher professionalism: An innovative programme for teaching mathematics to foundation level children with limited language proficiency. Early Childhood Development and Care, 173(2-3), 293-315.

Perry, M. (2000). Explanations of mathematical concepts in Japanese, Chinese, and U.S. first- and fifth- grade classrooms. Cognition and Instruction, 18 (2):181- 207.

Poulson, L. (2001). Paradigm lost? Knowledge, primary teachers and education policy. British Journal of Educational Studies, 49(1) 4055.

Sharma, Mahesh 1989. How children learn mathematics: Professor Mahesh Sharma, in interview with Bill Domoney. London, England: Oxford Polytechnic, School of Education. 90 min. Educational Methods Unit. Video cassette

Shulman, L. S. (1986). Those who understand: knowledge growth in teaching, Educational Researcher, 15 (2), 4-14.

Vaidya, S. R. (2008). Understanding dyscalculia for teaching. Education Vol. 124(4) pp?

Van de Walle, J.A. (2004). Elementary and middle school mathematics (5th Ed). Boston, MA: Pearson Education Inc.

Van Kraayenoord, C.E., \& Elkins, J. (2004). Learning difficulties in numeracy in Australia. Journal of Learning Disabilities, 37(1) 32-41.

Vygotsky, L. (1978). Mind in society. Cambridge: Harvard University Press.

Welch, T. Reaching Teachers? Curriculum challenges for distance teacher education in South Africa. Africa Education Review 5(2):324 $-327$.

White, C.J. (2005). Research: a practical guide. Pretoria. Ithuthuko Investment (Publishing). 